\title{
Entrepreneurship competences in business plans: a systematic literature review
}

\author{
Raquel Ferreras \\ Universitat Oberta de Catalunya \\ rferreras@uoc.edu \\ Ana Beatriz Hernández-Lara \\ Universitat Rovira i Virgili \\ anabeatriz.hernandez@urv.cat \\ Enric Serradell-López \\ Universitat Oberta de Catalunya \\ eserradell@uoc.edu
}

\begin{abstract}
This paper presents the results of a systematic literature review regarding the incorporation of entrepreneurial skills in bigher education, specifically through the evaluation of the acquisition of this type of competences when doing a business plan.

As a result of the large amount of literature on entrepreneurial skills, we think that a systematic literature review on this subject will be useful in order to clarify, systematize and determine what it is already known and the gaps that still remain in this academic field. A systematic literature review will allow us to determine the relevance given by research to this subject and its trajectory.

Therefore, in this article we will elaborate a state of the art on the incorporation of entrepreneurial competences at various levels: in education, in bigher education, and more specifically in the business plans.

The study of competences has been widely analyzed in recent decades due to its incorporation in teaching and learning. The abundance of literature on this matter
\end{abstract}


justify the suitability of conducting a systematic literature review, additionally to the classical revision of contents.

We carried out the systematic review of the literature using the database Web of Science from the first paper on this matter to the present. The procedure has been to narrow the search by determining the key concepts and combining them properly. In order to identify those studies, that in one way or another, are related to the topic of entrepreneurship and education, the generic keywords considered were entrepreneurship and entrepreneurship competences, while the specific keywords were business plans, education, teaching, learning, evaluation and university. Then we have identified the articles, we have exported to a reference management software, and finally we have reviewed the selected articles and discarded the ones that did not comply with the research theme.

The results show that in recent years, with the reforms involved in the Bologna Process, studies on entrepreneurial skills and their relationship with the teaching/ learning process have risen considerably. Thus, we have seen that in the scientific literature there are many experiences that include the study of competences or entrepreneurial competences in general and its relationship to education. However, to our knowledge, there are not studies that analyze the achievement of entrepreneurial competences by students when developing a business plan.

Keywords: Business plan, entrepreneurship, competences, systematic literature review.

Las competencias del emprendimiento y su papel en los planes de negocio: una revisión literaria sistemática

\section{Resumen}

En este artículo se presentan los resultados de una revisión sistemática de la literatura sobre la incorporación de las competencias emprendedoras en la educación superior, especificamente a través de la evaluación de la adquisición de este tipo de competencias al realizar un plan de empresa.

Como resultado de la gran cantidad de literatura sobre competencias emprendedoras, pensamos que una revisión sistemática de la literatura sobre este tema será útil para aclarar, sistematizar y determinar lo que ya se conoce y las lagunas que aún quedan en este campo académico. Una revisión sistemática de la literatura nos permitirá determinar la importancia de la relevancia dada por la investigación a este tema y su trayectoria.

Por lo tanto, en este artículo vamos a elaborar un estado del arte sobre la incorporación de las competencias emprendedoras a distintos niveles: en la educación, en la educación superior, y más específicamente en los planes de empresa. 
El estudio de las competencias ha sido ampliamente analizado en las últimas décadas debido a su incorporación en la enseñanza y el aprendizaje. La abundancia de literatura sobre este tema justifica la idoneidad de realizar una revisión sistemática de la literatura, además de la revisión clásica de los contenidos.

La revisión sistemática de la literatura la llevamos a cabo a partir de la base de datos Web of Science desde el primer trabajo sobre esta materia hasta el momento actual. El procedimiento ba consistido en restringir la búsqueda determinando los conceptos clave y combinándolos adecuadamente. Con el objetivo de identificar aquellos estudios que, de una u otra manera, están relacionados con el tema del emprendimiento y la educación, las palabras clave genéricas consideradas fueron emprendimiento y competencias emprendedoras, mientras que las palabras clave especificas fueron planes de empresa, educación, enseñanza, aprendizaje, evaluación y universidad. A continuación, hemos identificado los artículos, y los hemos exportado a un software de gestión de referencias, $y$ finalmente hemos revisado los artículos seleccionados resultantes $y$ descartado los que no se adecuan al tema de la investigación.

Los resultados muestran que en los últimos años, con las reformas del Proceso de Bolonia, se han incrementado considerablemente los estudios sobre competencias emprendedoras y su relación con el proceso de enseñanza/aprendizaje. Así, hemos observado que en la literatura cientifica existen muchas experiencias que incluyen el estudio de las competencias o de las competencias emprendedoras en general y su relación con la educación. Sin embargo, no conocemos ningún estudio que analice el grado de adquisición de las competencias emprendedoras por parte de los estudiantes al desarrollar un plan de empresa.

Palabras clave: plan de empresa, emprendimiento, competencias, revisión sistemática de la literatura. 


\section{Introduction}

Before carrying out a literature review, it is necessary to ensure that this is necessary and will add knowledge to the existing prior studies.

Due to the large amount of literature on entrepreneurial competences (Mitchelmore and Rowley, 2010), we decided to conduct a systematic review of the literature on this subject in the specific field of education in order to ascertain, systematize and determine the consensus on the subject in the literature. The study of this subject has been widely discussed in recent decades, when the concept of competence has attracted particular interest as a result of its inclusion in teaching and learning processes. It should also be noted that a literature review needs to be a systematic and not merely a traditional review of content precisely when there is a great deal of literature on a subject (Sánchez-Meca, 2010).

This paper aims to perform a systematic review of the literature on entrepreneurial competences and their relationship with teaching and learning at the university level. After conducting a thorough analysis of the literature, we found no study that had performed a review of this nature. The study by Mitchelmore and Rowley (2010) aims to carry out a review of the literature on entrepreneurial competences but from a more generic perspective. For this reason, we have decided to perform a systematic literature review to identify the existing literature on the subject, and to find out more about the scientific production in this area of knowledge.

So, first we describe what a systematic review of the literature is, then we justify the need of conducting this review and detail the methodology that allows us to understand the parameters used, then we show the results and finally we present the conclusions of the analysis.

\section{The review process}

A systematic literature review is essential in any academic project. According to Kitchenham (2004), a systematic review primarily involves defining a review protocol to assess and interpret all the relevant research on a specific research question, a subject area or a phenomenon of interest.

The literature review consists of conducting a comprehensive search of all articles on the subject studied, using search criteria for the subsequent selection of a collection of articles. According to Cook et alii (1997), the technique involves recording all the search criteria used in order to have a script of the decisions taken and the procedures followed, so that the search can be replicated at a later date if necessary. The results of a search on a particular topic are thereby 
quantitatively integrated in order to establish what the evidence has shown up to that point (Sánchez-Meca, 2010).

Kitchenham (2004) gives no detailed instructions on how to carry out these reviews, thus we have focused on the methodological proposals of Oates (2006) and Tranfield et alii (2003).

Oates (2006) divides the literature review process into six different activities: search, acquisition, evaluation, reading, critical evaluation and critical review. These activities are also compatible with the phases proposed by Tranfield et al. (2003), which Gonzales and Hernández (2016) adapted in their review on corporate governance. The steps to be followed in a systematic review adapted to our subject of study can therefore be summarised as follows:

- Planning of the systematic review, identifying the appropriate resources (databases, period, etc.) for performing the searches.

- Delimitation of the search, determining the key concepts and considering different alternatives for each concept, and combining them as appropriate.

+ Identification of the articles.

- Export of the articles to a reference manager for subsequent review.

- A review of the resulting articles, discarding those that are not relevant to the research subject.

We simultaneously incorporated the phases proposed by Sánchez-Meca (2010) in order to systematize the search. According to Sánchez-Meca (2010), the method for a systematic review of the literature consists of the following phases: identifying the journals in the discipline, establishing the relevant journals, creating the database with articles, analysis of the authors and articles, and analysis of keywords.

We discuss below how we carried out the stages in the systematic literature review in terms of both the methodology and the results.

\section{Methodology}

\subsection{Determining the research protocol}

In order to carry out the search for the most relevant articles, we used the following protocol:

a) Selection of the bibliographic database to perform the search. We consulted one of the most widely accepted and prestigious in academia as a consultation resource, the Web of Science. This database contains the leading journals and conferences in various fields of knowledge. 
b) Delimitation of the search, determining the key concepts to be considered, bearing in mind different alternatives for each concept and combining them as appropriate.

c) Setting of the criteria for selection and inclusion or exclusion of an article from the literature review. The search period is between 1971 and 2015. 1971 is not established as a lower bound of the search period, but it is the first year in which some work on topics of study appeared published.

\subsection{Identification of keywords}

Webster and Watson (2002) argue that a high-quality literature review must be complete and must focus on concepts, as concepts determine the structure and organisation of a literature review.

The keywords we decided to use are those related to the field of study of this project, which could be divided into two main areas: generic and specific. This means that, on the one hand, we will have very open terms which provide a large number of records that are not relevant to the study area analyzed when we perform the literature search individually, while, on the other hand, we will have closed terms which will give search results that are much more closely related to our topic when combined with those in the other group.

The generic fields that we used to perform the search are ENTREPRENEURIAL COMPETENCES and ENTREPRENEURSHIP, while the specific fields were BUSINESS PLANS, EDUCATION, TEACHING, LEARNING, EVALUATION and UNIVERSiTy. The reason for selecting these words was that we were trying to identify the studies which related entrepreneurship to the topic of education.

The search was initially conducted ${ }^{1}$ for these concepts separately, which gave a first impression of their importance from a quantitative standpoint. However, as expected, the fact that these concepts were highly generic generated a large number of articles related to the subject. As a result, according to the strategy defined in the previous section, we started the search and selected documents according to the defined criteria.

Combinations of keywords were made subject to the proviso that one of the generic concepts in the area of entrepreneurship had to be linked to one or more specific concepts in education. 17 combinations of keywords were thereby considered, including variations using the wildcard*. Interestingly, only 16 of the 17 searches were in fact keyword combinations, as we did not consider the field «entrepreneur* competenc ${ }^{*} »$ a combination in the strictest sense, but we decided

1 The Web of Science search was carried out using the search criteria "Title", i.e. the keywords had to be included in the title of the article. The search option using the search criteria "Subject" was discarded, as this search resulted in a very wide range of records which were not in the subject of study or were duplicates. 
to include it due to the relevance of this concept in our research. Furthermore, the «entrepreneur ${ }^{*}$ » field alone gave a total of 24.488 results and was therefore not included in the search.

Moreover, the reason for using only the root of the word in the search in some cases while using the wildcard ${ }^{*}$ is that some concepts have different words associated with the same root, and they all produce good search results. For example, the concept of competence can yield good results if we are searching for words such as competence, competency, competencies or competences. By using the asterisk in a single search, we cover the same concept regardless of the term used. The same is true of the concept of entrepreneurship, where, by using the field «entrepreneur», we included terms such as entrepreneurship, entrepreneurial, entrepreneur and entrepreneurs in the search.

The results of the search included 411 international publications, of which 312 were selected after excluding duplicates and those covering residual subjects. Other combinations were also performed and rejected due to the large number of records found that were not in the research area. Table 1 lists the international documents found, classified according to the search string and the result, depending on whether the paper included the selected combination in the title.

Table 1. Documents found in the Web of Science database by keywords

\begin{tabular}{|c|c|c|c|c|}
\hline \multicolumn{3}{|l|}{ Keywords } & \multirow{2}{*}{$\begin{array}{c}\text { Results per title } \\
197\end{array}$} & \multirow{2}{*}{$\begin{array}{c}\text { Articles included } \\
143\end{array}$} \\
\hline entrepreneur $^{*}$ competenc ${ }^{*}$ & & & & \\
\hline entrepreneur $^{\star}$ competenc $^{*}$ & business plan * & & 1 & 1 \\
\hline entrepreneur $^{*}$ competenc ${ }^{*}$ & teaching & & 1 & 1 \\
\hline entrepreneur $^{*}$ competenc $^{*}$ & learning & & 15 & 13 \\
\hline entrepreneur $^{*}$ competenc $^{*}$ & education & & 21 & 18 \\
\hline entrepreneur ${ }^{*}$ competenc ${ }^{*}$ & evaluation & & 3 & 3 \\
\hline entrepreneur ${ }^{*}$ competenc ${ }^{*}$ & universit* & & 13 & 11 \\
\hline entrepreneur ${ }^{*}$ & business plan* & & 29 & 23 \\
\hline entrepreneur ${ }^{*}$ & teaching & learning & 13 & 12 \\
\hline entrepreneur ${ }^{\star}$ & teaching & education & 19 & 12 \\
\hline entrepreneur ${ }^{\star}$ & teaching & evaluation & 1 & 1 \\
\hline entrepreneur ${ }^{*}$ & teaching & universit* & 14 & 10 \\
\hline entrepreneur ${ }^{\star}$ & learning & education & 47 & 36 \\
\hline entrepreneur ${ }^{*}$ & learning & evaluation & 3 & 3 \\
\hline entrepreneur* & learning & universit $^{\star}$ & 14 & 13 \\
\hline entrepreneur ${ }^{*}$ & education & evaluation & 12 & 12 \\
\hline entrepreneur ${ }^{\star}$ & evaluation & universit $^{\star}$ & 8 & 0 \\
\hline \multicolumn{3}{|l|}{ Total } & 411 & 312 \\
\hline
\end{tabular}

Source: Elaborated by the authors based on information of Web of Knowledge database (2016) 
Most articles refer to the subject of «entrepreneurial competences» (46\%), which is understandable as it is one of the broadest concepts included in the search. The next search field in terms of volume of articles is the combination of «entrepreneurial competences, learning and education», with $12 \%$, followed by «entrepreneurship and business plans», with 7\%. These results are shown in Fig. 1.

Fig* 1. Articles located in the Web of Science database by search string

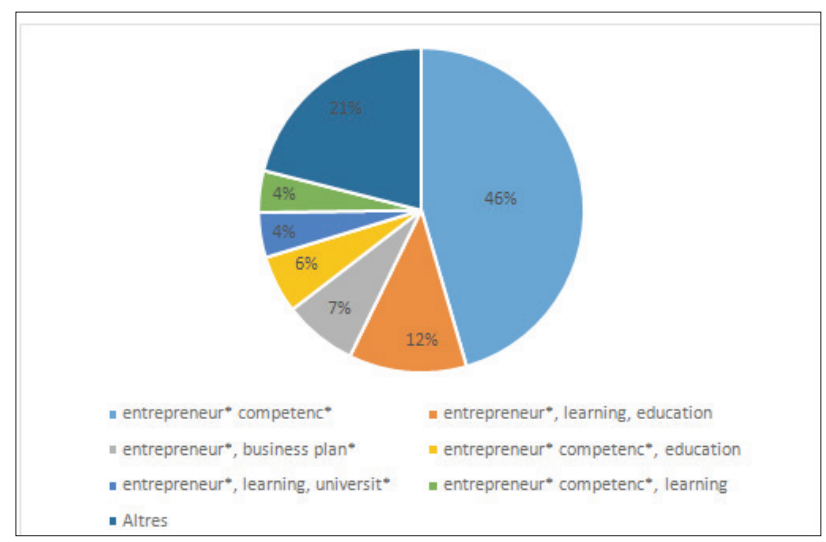

Source: Elaborated by the authors based on information of Web of Knowledge database (2016)

In the searches carried out, and after reading the abstracts of the articles, there was no article that analyzed the main subject of study of this work, i.e. evaluation of entrepreneurial competences by means of business plans.

\section{Systematic analysis of the results}

\subsection{Analysis of the number of articles according to the journal and the year of publication}

To facilitate the analysis and categorization of the references, we analyzed the search carried out in the field of study, taking into account the journals in which the studies were published and the year of publication. These results show the growing trend in the number of publications as we approach the last decade.

The analysis and synthesis of data shows that among all the journals included, those with the highest number of articles published on the subject are the Handbook of Research in Entrepreneurship Education; International Conference of Education, Research and Innovation; Proceedings of the European Conference on Innovation and Entrepreneurship; and Quality Management in Higher Education, with 9, 8, 7 and 7 articles published, respectively. However, 
the largest category is composed by journals that have published only one article, included in the "Other» category, a total of 103 journals. On the other hand, it is also interesting that 85 articles are from conferences and that the majority of these conference articles have been published since 2008, when the increase in specialised conferences on the subject began.

As it is apparent, this subject of study has mainly been present in the literature in the last decade. In specific terms, the most significant growth has taken place since 2007, when the Bologna Plan for convergence towards the European Higher Education Area began to be implemented. Academic interest in competences has shown a tendency to increase over the years, as shown in Fig. 2. Most of the studies, $89 \%$ of all the articles considered, were therefore published in the last decade.

Fig. 2. Year of publication and number of articles published

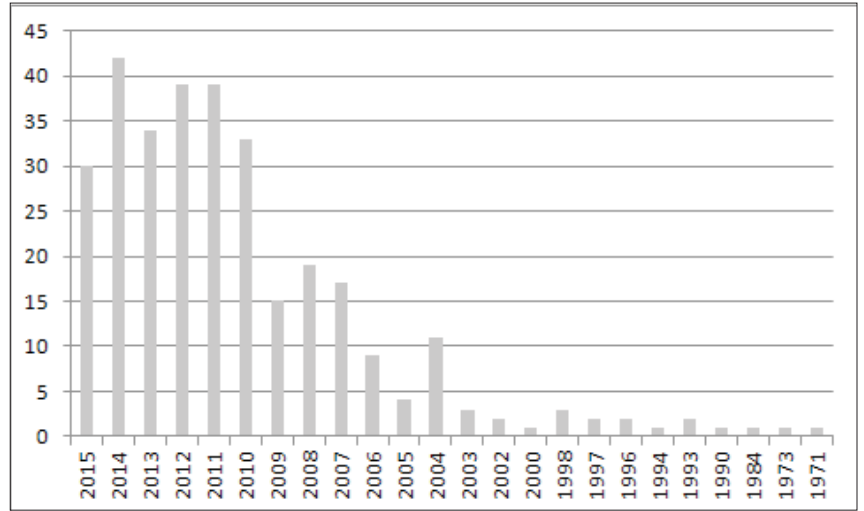

Source: Elaborated by the authors based on information of Web of Knowledge database (2016)

Finally, Table 2 presents an analysis by geographical area and a breakdown of the publications according to the country of origin of the journals, with the United Kingdom, with 25,6\%, and the United States, with 22,8\%, being the two countries of origin of publications with the highest number of studies on the subject. This is not surprising for two reasons: the influence of English language publications in the database and the more long-standing tradition of research in this particular area. The diversity of countries publishing specialised articles on the research subject is also interesting, and includes Asian countries such as China and Korea, with $10 \%$ of the publications, and European countries. The European countries, despite not having as many publications as the top two, they account for a significant amount of research in global terms, at $26,3 \%$ of the publications. 
Table 2. Geographic area of the journal

\begin{tabular}{|l|c|}
\hline \multicolumn{1}{|c|}{ Country } & Number of articles \\
\hline United Kingdom & 80 \\
\hline United States & 71 \\
\hline Netherlands & 27 \\
\hline Spain & 21 \\
\hline Korea & 19 \\
\hline Romania & 15 \\
\hline China & 12 \\
\hline Germany & 9 \\
\hline Australia & 8 \\
\hline Singapore & 6 \\
\hline Greece & 5 \\
\hline Italy & 5 \\
\hline Other & 34 \\
\hline Total & 312 \\
\hline
\end{tabular}

* The «Other» category includes all the countries for which the number of articles published is 4 or less.

Source: Elaborated by the authors based on information of Web of Knowledge database (2016)

\subsection{Analysis by research area and category}

According to Webster and Watson (2002), an effective review provides the basis for progress in knowledge of the subject, and facilitates development and knowledge of the areas analyzed.

In this section, we carried out an additional classification to determine the focus of the selected articles in more detail. The references were therefore analyzed and classified by area and research category as catalogued on the Web of Science. This approach determines the areas most closely related to the subject of study of entrepreneurial competences.

Tables $^{2} 3$ and 4 show the number of articles found in the database according to the research area and category, respectively.

2 A single article may refer to different research areas and categories. According to the Web of Science database, 422 assignments were made in 314 publications according to the research area, and 491 assignments were made according to the research category. These assignments depend on the title of the article or book, the keywords 
An analysis of the data in Table 3 shows that most articles in our study area are catalogued in the research areas of Business $\&$ Economics and Education $\&$ Educational Research, followed at some distance by the area of Social Sciences. In specific terms, Table 5 shows that $43 \%$ of the articles fall within the area of Business \& Economics, $24 \%$ of the articles in the area of Education $\&$ Educational Research, and $6 \%$ of the articles in the area of Social Sciences. It is not until the final positions, which can be described as residual, that articles catalogued in the areas of Engineering, Psychology, Operations Research \& Management Science, Computer Science and Public Administration appear, all with percentages below $4 \%$.

Table 3. Research area of the publications

\begin{tabular}{|c|c|c|}
\hline Research area & Number of articles & Percentage \\
\hline Business \& Economics & 182 & 43,1 \\
\hline Education \& Educational Research & 103 & 24,4 \\
\hline Social Sciences - Other Topics & 24 & 5,7 \\
\hline Engineering & 19 & 4,5 \\
\hline Psychology & 19 & 4,5 \\
\hline Operations Research \& Management Science & 17 & 4 \\
\hline Computer Science & 15 & 3,6 \\
\hline Public Administration & 13 & 3,1 \\
\hline Other ${ }^{*}$ & 30 & 7,1 \\
\hline Total & 422 & 100 \\
\hline
\end{tabular}

* The «Other» category includes all the areas in which the number of articles published is 6 or less.

Source: Elaborated by the authors based on information of Web of Knowledge database (2016)

An analysis of the data in Table 4 shows that, as expected, after confirmation that the most common research areas are Business $\&$ Economics and Education $\&$ Educational Research, the articles are classified into four main categories: Management, Education \& Educational Research, Business, and Economics. As in the previous classification, this is evidenced by the close relationship between our research area, which focuses on education and entrepreneurship, and the categories obtained. If we focus on the data in more detail, we find that $23 \%$ of

and the journal in which it was published. The percentages in this analysis were calculated on the basis of the assignments made. 
the articles are catalogued in the category of Management, $20 \%$ in the category of Education \& Educational Research, 18\% in the category of Business and $7 \%$ in the category of Economics. These primary categories are followed by a number of secondary categories, headed by the Social Sciences category with $4 \%$ of the published articles, which makes it the third area of research in terms of volume of publications. In general terms, the remaining areas were residual, with percentages below $3 \%$.

Table 4. Category of publications

\begin{tabular}{|l|c|c|}
\hline \multicolumn{1}{|c|}{ Category } & Number of articles & Percentage \\
\hline Management & 113 & 23 \\
\hline Education \& Educational Research & 99 & 20,2 \\
\hline Business & 89 & 18,1 \\
\hline Economics & 36 & 7,3 \\
\hline Social Sciences, Interdisciplinary & 21 & 4,3 \\
\hline Operations Research \& Management Science & 17 & 3,5 \\
\hline Computer Science, Information Systems & 12 & 2,4 \\
\hline Planning \& Development & 10 & 2 \\
\hline Psychology, Multidisciplinary & 10 & 2 \\
\hline Engineering, Industrial & 8 & 1,6 \\
\hline Education, Scientific Disciplines & 7 & 1,5 \\
\hline Other & 69 & 14,1 \\
\hline Total & 491 & 100 \\
\hline
\end{tabular}

* The "Other" category includes all the categories in which the number of articles published is 5 or less.

Source: Elaborated by the authors based on information of Web of Knowledge database (2016)

\subsection{Analysis by keywords}

A review of the contents of the selected articles enabled us to extract the keywords mentioned in publications. We counted all the keywords found in the abstracts of the articles selected, ordering them from greater to lesser frequency. The total number of keywords found was $5.47^{3}$, of which 447 were named in only one article, and 55 in two articles. We used two criteria to select the keywords: the

3 The keyword count was performed considering only the different keywords found in the abstract, without taking into account the number of times they were repeated. 
first was that the keyword had to be related to the subject of the study, and the second criterion was that the frequency of appearance of the keyword had to be greater than 4 counts. As a result, we finally considered 18 keywords from the 547 different keywords as being the most representative of our research area.

Table 5 illustrates the main keywords found and the number of times they are cited, as well as the percentage of the total selected keywords. Although the other keywords are not shown, they included words such as business, business plan, entrepreneurial education, entrepreneurial skills and skills, which were the next to appear in the compilation obtained, with four appearances each, and they are also closely related to our research.

Table 5. Keywords obtained from the articles

\begin{tabular}{|l|c|c|}
\hline \multicolumn{1}{|c|}{ Keywords } & Number & Percentage \\
\hline entrepreneurship $^{\prime}$ & 53 & 21,9 \\
\hline competenc $^{*}$ & 31 & 12,8 \\
\hline entrepreneurial competenc $^{*}$ & 29 & 12,0 \\
\hline entrepreneurship education $^{\prime}$ & 28 & 11,6 \\
\hline entrepreneurs $^{\prime}$ & 14 & 5,8 \\
\hline higher education & 13 & 5,4 \\
\hline education & 10 & 4,1 \\
\hline core competenc $^{*}$ & 8 & 3,3 \\
\hline innovation & 8 & 3,3 \\
\hline e-learning & 6 & 2,5 \\
\hline entrepreneurial learning & 6 & 2,5 \\
\hline social entrepreneurship & 6 & 2,5 \\
\hline entrepreneurial & 5 & 2,1 \\
\hline entrepreneurship competenc* & 5 & 2,1 \\
\hline learning & 5 & 2,1 \\
\hline performance & 5 & 2,1 \\
\hline Small Medium Sized Enterprises (SME) & 5 & 2,1 \\
\hline teaching & 5 & 2,1 \\
\hline Total & 242 & 100 \\
\hline
\end{tabular}

Source: Elaborated by the authors based on information of Web of Knowledge database (2016)

From the data obtained, the keywords that appear most often in the selected articles are those related to entrepreneurship (entrepreneurship, entrepreneurs and entrepreneurial), with $29,8 \%$ of the occurrences; those related to 
competences ( competenc $^{*}$ and core competenc ${ }^{\star}$ ), with $16,1 \%$; those related to more specific subjects, such as entrepreneurship competences (entrepreneurial competenc $^{*}$ and entrepreneurship competenc ${ }^{*}$ ), with $14,1 \%$; and finally those related to education and entrepreneurship (entrepreneurship education and entrepreneurial learning), with another $14,1 \%$ of the citations.

Fig. 3. Keywords

\begin{tabular}{|c|c|c|}
\hline \multicolumn{3}{|c|}{ Generic subjects } \\
\hline Entrepreneurship & Competences & Education \\
\hline \multicolumn{3}{|c|}{ Specific subjects } \\
\hline Business & Entrepreneurial competences & Entrepreneurial education \\
\hline \multicolumn{3}{|c|}{ Keywords } \\
\hline Entrepreneurship & Competences & Education \\
\hline Social entrepreneurship & Entrepreneurial competences & Entrepreneurial education \\
\hline Entrepreneurs & Basic competences & Higher education \\
\hline Innovation & & Teaching \\
\hline Performance & & Learning \\
\hline \multirow[t]{2}{*}{ SME } & & e-learning \\
\hline & & Entrepreneurial learning \\
\hline
\end{tabular}

Source: Elaborated by the authors

These data are not surprising, since they are determined by having selected certain specific keywords when performing the search. However, it should be noted that although there are terms with the same importance in the search, the term entrepreneurship appears more often than the term competenc ${ }^{*}$, at 53 versus 31 counts, which highlights the area of interest of researchers in this field. Furthermore, the individual (the entrepreneur) appears only 14 times in the search, which is a factor that should be analyzed in depth in future research. Competences appear many more times (31) than the more generic term of education, which only appears 10 times. This may be explained by the adaptation of curricula to evaluation by competences in recent years. Another conclusion 
that can be drawn from the table is that the term «entrepreneurship» is linked to many other variables, such as competences, education, learning and the term «social».

An analysis of the keywords obtained from the abstracts of the 312 articles enabled us to identify five main themes related to our research subject. These main themes can be broadly grouped into three generic subjects, which are entrepreneurship, competences and education, and, on the other hand, three specific subjects related to business, entrepreneurial competences and entrepreneurial education. Fig. 3 shows the groupings by subject and associated keywords.

\section{Conclusions}

A review of the literature can be considered successful if it informs the reader about what has been learned. To conclude, we can state there is a growing interest in the study of entrepreneurial competences and their relationship with education. We have observed that the number of publications has increased essentially since 2007 and the Bologna Plan. We have therefore seen that the scientific literature contains many experiences that include the study of entrepreneurial competences or competences in general and their relationship to education. Although the experiences analyzed are valid, none of them appears to be a complete and generalizable model. This justifies expanding the scope of the research and attempting to contribute to the subject studied.

Additionally, although headings are the appropriate instruments for the evaluation of competences and are used repeatedly, and a number of papers include teaching and learning of entrepreneurial competences, the literature reviewed does not give explicit details of any system ensuring the relevant information about them, or evaluating the achievement of competences in education.

The aim of our study is fully justified because of the consensus on the importance of entrepreneurial competences in the academic and professional world. We also wish to contribute knowledge and to try, resolve and study some of the research that has not been previously analyzed in depth, in the absence of any previous study with the same characteristics designed for a completely virtual learning environment. Progress in the design of methodologies to assess entrepreneurial competences is therefore the objective of this research. 


\section{References}

Cook, D.J.; Mulrow, C.D. and Haynes, R.B. (1997). «Systematic reviews: synthesis of best evidence for clinical decisions». Annals of Internal Medicine, $126(5) \div 376-80$.

Gonzales-Bustos, J.P. and Hernández-Lara, A.B. (2016). "Corporate governance and innovation: A systematic literature review». Corporate Ownership and Control, 13(2): 33-45.

Kitchenham, B. (2004). Procedures for performing systematic reviews. Keele University Technical Report TR/SE-0401.

Mitchelmore, S. and Rowley, J. (2010). «Entrepreneurial competencies: a literature review and development agenda». International journal of entrepreneurial Behavior E Research, 16(2): 92-111.

Oates, B.J. (2006). Researching information systems and computing. London, Sage Publications.

Sánchez-Meca, J. (2010). "Cómo realizar una revisión sistemática y un metaanálisis». Aula abierta, 38: 53-64.

Tranfield, D.; Denyer, D. and Smart, P. (2003). «Towards a methodology for developing evidence-Informed management knowledge by Means of systematic review». British Journal of Management, 14(3): 207-222.

Webster, J. and Watson, R. (2002). «Analyzing the past to prepare for the future: writing a literature review», Revista MIS Quarterly, 26(2): 13-23. 